\title{
What articles are in scope for the Journal of Transport and Health?
}

The Journal of Transport \& Health is devoted to publishing research that advances our knowledge on the many interactions between transport and health and the policies that affect these. Almost anything that affects transport can affect health but this journal cannot - and we would not wish to - publish all the high quality papers that there are in the field of transport [transportation]. Five years after starting the Journal of Transport and Health the journal Board members and editors reviewed the journal's scope.

We wish the Journal of Transport and Health to publish cutting-edge articles that are significant for policy and practice. The readership is international and multi-disciplinary; articles need to be understood by intelligent readers from a broad range of specialties and places. We are particularly keen to encourage submissions that are cross-disciplinary or inter-disciplinary. The journal aims to cover transport and health issues in all countries; in general, studies should have a context, or lessons, that can be transferred to other locations. The revised scope is now on the journal's Home page (https://www.journals.elsevier.com/journal-of-transport-and-health/) . We include a reminder that to be considered for the journal, the manuscript must focus on both transport and health. We have also added guidance on what is and what is not considered in scope.

\section{Active travel}

Is it important to know how children and young people travel to and from school or college in your area? Yes, it is important for local practitioners and policy-makers, as well as for researchers designing and evaluating interventions. School travel surveys have been validated (Evenson et al. 2008) and widely used for many years (e.g. DiGuiseppi et al. 1998; McDonald 2008; McMillan 2007). Since 2014 we have published studies on school travel from across the world, including China (Sun et al. 2018); Iran (Mehdizadeh et al. 2017); Spain (Aibar Solana et al. 2018); the Czech Republic (Hollein et al. 2017); Denmark (Christiansen et al. 2014); Portugal (Pizarro et al. 2016); the UK (Carver et al. 2014); Australia (Schoeppe et al. 2015); New Zealand (Mandic et al. 2017); Canada (Mammen et al. 2014); and Brazil (Sá et al. 2015). Like surveys of smoking prevalence, or other behavioural risk factors in other journals, the evidence base has moved on and simple reports of surveys of school travel are no longer appropriate for publication in an international peer-reviewed journal unless they go substantially further than documenting the proportion of children travelling by a particular mode.

In general, we will prioritise papers that evaluate or inform the development of interventions and policies to improve population health, or that make a genuinely original contribution, rather than basic descriptive studies. More complex studies include assessment of school commuting in relation to: school enrolment and choice (Mandic et al. 2017); school travel policies (Hollein et al. 2017); perceptions of walking time to school (Mehdizadeh et al. 2017); the built environment (Mammen et al. 2014; Sun et al. 2018); and interventions (Christiansen et al. 2014).

We look forward to receiving more accounts of interventions to promote active travel - regardless of whether or not the intervention was actually successful, as it is also important to know what did not work (e.g. Christiansen et al. 2014) - and other longitudinal studies (e.g. Falconer et al. 2015). While Swiers and colleagues (2017) surveyed UK university students about their attitudes and behaviours regarding cycling, Wilson et al (2018) examined the successful policies that universities in the USA have used to encourage cycling by students and staff. Orozco-Fontalvo and colleagues (2018) used economics techniques when modelling cycling choice in Colombia, and Morckel (2016) used structural equation modelling to consider perceptions and physical activity by university staff. 


\section{Road travel injuries}

We are also becoming more restrictive regarding manuscripts reporting studies on travel crashes. Another editorial in this volume considers Vision Zero (Christie, 2018) and what might be required to achieve it. There are many other journals devoted to analysis or prevention of injuries, crashes, or 'accidents', travel-related or otherwise. Of course these events may have health consequences, but we do not intend to replicate the work of other journals. We ask authors to submit to the Journal of Transport and Health articles that focus on health rather than on factors associated with collisions.

We look forward to reading your submissions. We ask that you read the journal's scope on the home page (https://www.journals.elsevier.com/journal-of-transport-and-health/), as well as the Guide for authors (https://www.elsevier.com/journals/journal-of-transport-and-health/2214-1405/guide-forauthors) and Tips from the editor (https://www.journals.elsevier.com/journal-of-transport-andhealth/policies-and-guidelines/tips-on-writing-for-jth) before you submit your manuscript.

\section{References}

Aibar Solana, A., Mandic, S., Generelo Lanaspa, E., Gallardo, L.O., Zaragoza Casterad, J., 2018. Parental barriers to active commuting to school in children: does parental gender matter? Journal of Transport \& Health Vol 9 https://doi.org/10.1016/j.jth.2018.03.005.

Carver, A., Panter, J.R., Jones, A.P., van Sluijs, E.M.F., 2014. Independent mobility on the journey to school: A joint cross-sectional and prospective exploration of social and physical environmental influences. Journal of Transport \& Health 1, 25-32.

Christiansen, L.B., Toftager, M., Ersbøll, A.K., Troelsen, J., 2014. Effects of a Danish multicomponent physical activity intervention on active school transport. Journal of Transport \& Health 1, 174-181.

Christie N (2018). Is Vision Zero important for promoting health? (Editorial) Journal of Transport \& Health Vol 9

DiGuiseppi, C., Roberts, I., Li, L., Allen, D., 1998. Determinants of car travel on daily journeys to school: cross sectional survey of primary school children. BMJ 316, 1426-1428.

Evenson, K.R., Neelon, B., Ball, S.C., Vaughn, A., Ward, D.S., 2008. Validity and Reliability of a School Travel Survey. Journal of Physical Activity and Health 5, S1-S15.

Falconer, C.L., Leary, S.D., Page, A.S., Cooper, A.R., 2015. The tracking of active travel and its relationship with body composition in UK adolescents. Journal of Transport \& Health 2, 483-489.

Hollein, T., Vašíčková, J., Bucksch, J., Kalman, M., Sigmundová, D., Dijk, J.P.v., 2017. School physical activity policies and active transport to school among pupils in the Czech Republic. Journal of Transport \& Health 6, 306-312.

McDonald, N.C., 2008. Household interactions and children's school travel: the effect of parental work patterns on walking and biking to school. Journal of Transport Geography 16, 324-331.

McMillan, T.E., 2007. The relative influence of urban form on a child's travel mode to school. Transportation Research Part A: Policy and Practice 41, 69-79. 
Mammen, G., Stone, M.R., Buliung, R., Faulkner, G., 2014. School travel planning in Canada: Identifying child, family, and school-level characteristics associated with travel mode shift from driving to active school travel. Journal of Transport \& Health 1, 288-294.

Mandic, S., Sandretto, S., García Bengoechea, E., Hopkins, D., Moore, A., Rodda, J., Wilson, G., 2017. Enrolling in the Closest School or Not? Implications of school choice decisions for active transport to school. Journal of Transport \& Health 6, 347-357.

Mehdizadeh, M., Mamdoohi, A., Nordfjaern, T., 2017. Walking time to school, children's active school travel and their related factors. Journal of Transport \& Health 6, 313-326.

Morckel, V.C., 2016. Examining the relationships between perceived neighborhood mobility characteristics, perceived incivilities, travel attitudes, and physical activity amongst university faculty and staff. Journal of Transport \& Health 3, 86-95.

Orozco-Fontalvo, M., Arévalo-Támara, A., Guerrero-Barbosa, T., Gutiérrez-Torres, M., 2018. Bicycle choice modeling: A study of university trips in a small Colombian city. Journal of Transport \& Health Vol 9 https://doi.org/10.1016/j.jth.2018.01.014.

Pizarro, A.N., Schipperijn, J., Andersen, H.B., Ribeiro, J.C., Mota, J., Santos, M.P., 2016. Active commuting to school in Portuguese adolescents: Using PALMS to detect trips. Journal of Transport \& Health 3, 297-304.

Sá, T.H.d., Garcia, L.M.T., Mielke, G.I., Rabacow, F.M., Rezende, L.F.M.d., 2015. Changes in travel to school patterns among children and adolescents in the São Paulo Metropolitan Area, Brazil, 19972007. Journal of Transport \& Health 2, 143-150.

Schoeppe, S., Duncan, M.J., Badland, H.M., Oliver, M., Browne, M., 2015. Associations between children's active travel and levels of physical activity and sedentary behavior. Journal of Transport \& Health 2, 336-342.

Sun, G., Han, X., Sun, S., Oreskovic, N., 2018. Living in school catchment neighborhoods: Perceived built environments and active commuting behaviors of children in China. Journal of Transport \& Health 8, 251-261.

Swiers, R., Pritchard, C., Gee, I., 2017. A cross sectional survey of attitudes, behaviours, barriers and motivators to cycling in University students. Journal of Transport \& Health 6, 379-385.

Wilson, O., Vairo, N., Bopp, M., Sims, D., Dutt, K., Pinkos, B., 2018. Best practices for promoting cycling amongst university students and employees. Journal of Transport \& Health Vol 9. 